\title{
Simultaneous Estimation of Geophysical Parameters with Microwave Radiometer Data based on Accelerated Simulated Annealing: SA
}

\author{
Kohei Arai \\ Graduate School of Science and Engineering \\ Saga University \\ Saga City, Japan
}

\begin{abstract}
Method for geophysical parameter estimations with microwave radiometer data based on Simulated Annealing: SA is proposed. Geophysical parameters which are estimated with microwave radiometer data are closely related each other. Therefore simultaneous estimation makes constraints in accordance with the relations. On the other hand, $\mathrm{SA}$ requires huge computer resources for convergence. In order to accelerate convergence process, oscillated decreasing function is proposed for cool down function. Experimental results show that remarkable improvements are observed for geophysical parameter estimations.
\end{abstract}

Keywords- simulated annealing; microwave radiometer water vapor; air-temperature; wind speed.

\section{INTRODUCTION}

Microwave radiometer allows estimation of geophysical parameters such as water vapor, rainfall rate, ocean wind speed, salinity, soil moisture, air-temperature, sea surface temperature, cloud liquid, etc. based on least square method. Due to the fact that relation between microwave radiometer data (at sensor brightness temperature at the specified frequency) and geophysical parameters is non-linear, non-linear least square method is required for the estimations. Although there are some methods which allow estimation optimum solutions, Simulated Annealing: SA method is just one method for finding global optimum solution.

Other methods, such as steepest descending method, conjugate gradient method, etc. gives one of local minima, not the global optimum solution. SA, on the other hand, requires huge computer resources for convergence. In order to accelerate the convergence process, not the conventional exponential function with the temperature control, but osculated decreasing function is employed for cool down function. Geophysical parameter estimation based on simulated annealing is proposed previously [1]. It takes relatively long computational time for convergence. Moreover, optimization with constraints makes much accurate estimation of geophysical parameters. Some of the constraints is relation among the geophysical parameters.

Geophysical parameters have relations each other. For instance, sea surface temperature and water vapor has a positive relation, in general.
Therefore, it is better to estimate several geophysical parameters simultaneously rather than the estimation for single parameter. The proposed method is based on modified SA algorithm and is for simultaneous estimation for several geophysical parameters at once. Some experiments are conducted with Advanced Microwave Scanning Radiometer:

AMSR [2] onboard AQUA satellite. Then it is confirmed that the proposed method surely works for improvement of estimation accuracy for all the geophysical parameters.

The following section describes the proposed method followed by some experimental results. Then conclusion with some discussions is followed in the final section.

\section{PROPOSED METHOD}

\section{A. Schematic View of AMSR Observations}

AMSR onboard AQUA satellite observes sea surface through the atmosphere with absorptions due to atmospheric molecules, water vapor, aerosol particles as shown in Fig.1. Such atmospheric continuants also radiated depending on their temperature and emissivity. Attenuation due to absorption can be shown in Fig.2.

Using absorption spectrum due to water $(22.235 \mathrm{GHz})$, it is possible to estimate water vapor in the atmosphere. It also is possible to estimate air-temperature at the sea surface with much lower frequency channels, 5 to $10 \mathrm{GHz}$. Using oxygen absorption frequency, it is possible to estimate air temperature profile. Meanwhile, cloud liquid water can be estimated with around $37 \mathrm{GHz}$ frequency channel.
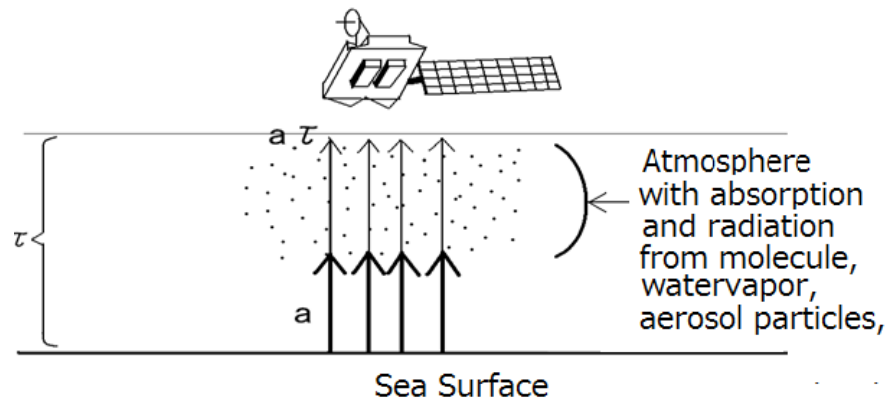

Figure 1 Radiative transfer from the sea surface to the AMSR onboard AQUA 


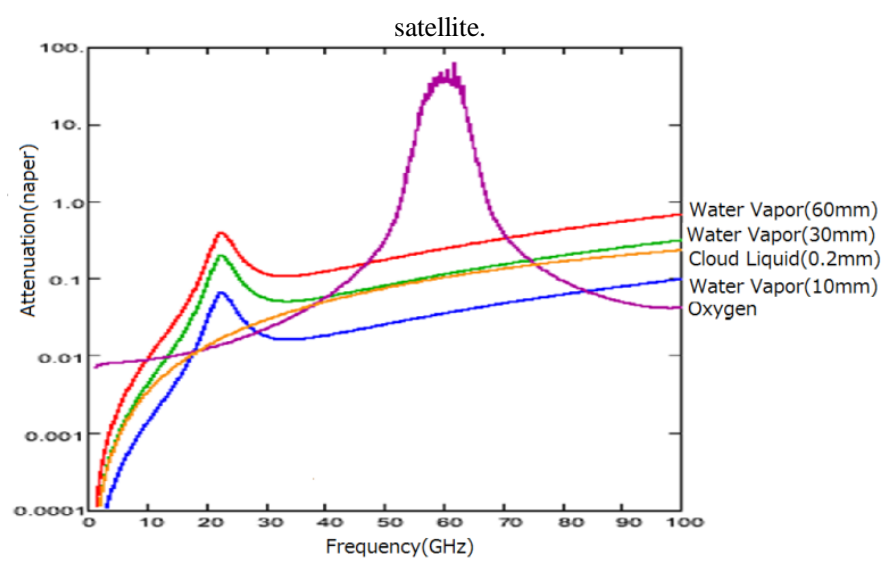

Figure 2 Attenuation due to atmospheric continuants, water vapor, cloud liquid, and oxygen.

On the other hand, there is sea surface model. Incident microwave energy (incident energy) reflects at the sea surface (radiant energy) and penetrates a little bit (transparent energy) as shown in Fig.3 (a). Sea surface can be modeled as shown in Fig. 3 (b). There are some models for shape of the ocean waves such as non-symmetrical Gaussian function. Depending on ocean wind speed, forms or bubbles are generated at the sea surface results in changing the emissivity of the sea surface. More detailed description of sea surface model is described in the following section.

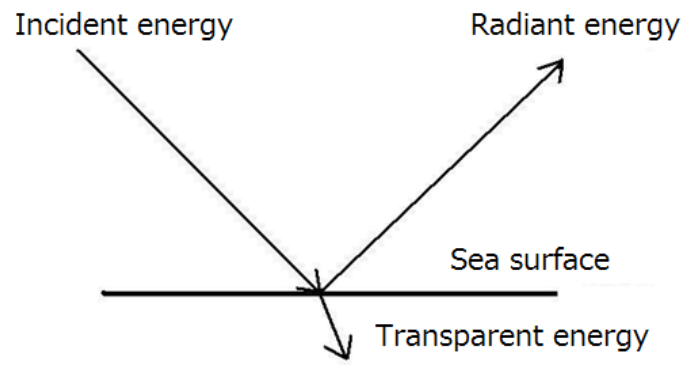

(a)

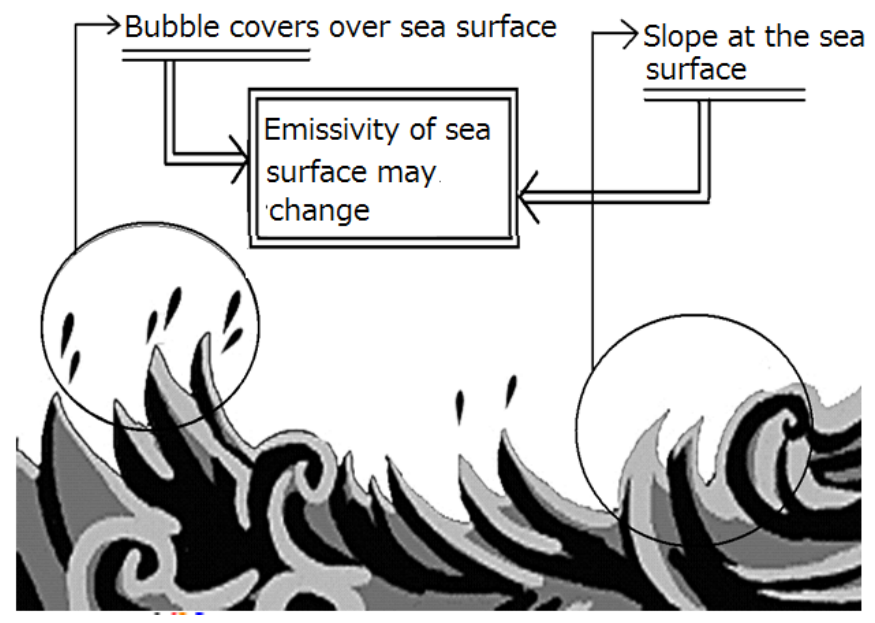

(b)

Figure 3 Sea surface model
Observed brightness temperature at AMSR can be expressed with equation (1).

$T_{B_{i}}=T_{B U}+\tau\left[\varepsilon_{j} T_{S}+T_{B \Omega_{j}}\right]$

where $T_{B i}, T_{B U}, \tau, \varepsilon, T_{S}, T_{B \Omega}$ are at sensor brightness temperature, radiance from the atmosphere, atmospheric transparency, sea surface emissivity, sea surface temperature, reflected atmospheric radiance at sea surface, respectively. Root Mean Square: RMS difference between actual brightness temperature acquired with microwave antenna and model based brightness temperature with geophysical parameters is expressed with equation (2).

$$
f\left(T_{S}, W, V\right)=\left|T_{B}-\left(T_{B U}+\tau\left[\varepsilon T_{S}+T_{B \Omega}\right]\right)\right|^{2}
$$

The RMS difference is a function of sea surface temperature, water vapor, ocean wind speed. Thus geophysical parameters can be estimated through minimization of the RMS difference.

\section{B. Observation Models}

There are some atmospheric and ocean surface models in the microwave wavelength region. Therefore, it is possible to estimate at sensor brightness temperature (microwave radiometer) with the geophysical parameters. The real and the imaginary part of dielectric constant of the calm ocean surface is modeled with the SST, salinity (conductivity). From the dielectric constant, reflectance of the ocean surface is estimated together with the emissivity (Debue, 1929 [3]; Cole and Cole, 1941 [4]). There are some geometric optics ocean surface models (Cox and Munk, 1954 [5]; Wilheit and Chang, 1980 [6]). According to the Wilheit model, the slant angle against the averaged ocean surface is expressed by Gaussian distribution function.

There is a relation between ocean wind speed and the variance of the Gaussian distribution function as a function of the observation frequency. Meanwhile the influence due to foams, white caps on the emissivity estimation is expressed with the wind speed and the observation frequency so that the emissivity of the ocean surface and wind speed is estimated with the observation frequency simultaneously. Meanwhile, the atmospheric absorptions due to oxygen, water vapor and liquid water were well modeled (Waters, 1976 [7]). Then atmospheric attenuation and the radiation from the atmosphere can be estimated using the models. Thus the at-sensor-brightness temperature is estimated with the assumed geophysical parameters.

Sea surface temperature estimation methods with AMSR data are proposed and published [8] while ocean wind retrieval methods with AMSR data are also proposed and investigated [9]. Furthermore, water vapor and cloud liquid estimation methods with AMSR data are proposed and studied [10].

The proposed method allows minimize the square of the difference between the actual brightness temperature with microwave radiometer onboard satellite and the estimated brightness temperature using simulated annealing with the assumed geophysical parameters. Then the geophysical 
parameters are estimated when the square of the difference shows the minimum.

In order to minimize the square of the difference between the actual and the estimated brightness temperatures, a nonlinear optimization method is used. Because the relation between the geophysical parameters and the brightness temperature is not linear so that nonlinear optimization methods are appropriate to use. Newton-Raphson iterative method, conjugate gradient method, etc., are well known and are widely used methods. These methods, however, do not ensure to reach the global optimum. These methods tend to fall in one of local minima. Only simulated annealing ensures to reach a global optimum solution.

At-sensor-brightness temperature, TB> is represented with equation (1). The first term of the equation (1) is the contribution from the atmosphere while the second term is that from the ocean surface which consists of the Sea Surface Temperature: SST of $T_{S}$ and the atmospheric radiance reflected at the ocean surface, $\mathrm{T}_{\mathrm{BX}}$. $\tau$ is the atmospheric transmittance and is expressed with equation (3).

$$
\tau\left(h_{1}, h_{2}, \theta\right)=\exp \left[-\sec \theta \int_{h_{1}}^{h_{2}} \alpha(h) \mathrm{d} h\right]
$$

where $\alpha$ denotes the absorption coefficient and $h$ is the observation angle while $\varepsilon$ denotes the emissivity of the ocean surface as a function of dielectric constant and the ocean winds. The first term of the equation (1) is represented as follows:

$$
T_{\mathrm{BU}}=\sec \theta \int_{0}^{H} \alpha(h) T(h) \tau(h, H, \theta) \mathrm{d} h
$$

where $T$ denotes air-temperature at the altitude of $h$. Thus the at-sensor-brightness temperature is estimated with the assumed geophysical parameters, SST, wind speed, water vapor and cloud water. Then the following cost function, the square of the difference between the actual AMSR brightness temperature, $T_{B}$ and the estimated brightness temperature, is defined as equation (2). Then simulated annealing finds the global optimum solution, the minimum cost function at which the best estimation of the set of the geophysical parameters.

The cloud water is ignored from the cost function because the cloud free data are selected for the experiment. In order to emphasize the effectiveness of the proposed method, cloud free data were reselected in this study. In this case the emissivity of the ocean surface is the function of SST and wind speed. Through a regressive analysis with the second order polynomial with a plenty of experimental data, the following empirical equations are derived for the observation frequency of $10.65 \mathrm{GHz}$ in normal direction.

The conventional geophysical parameter estimation method is based on regressive analysis with a plenty of truth data and the corresponding microwave radiometer data [11].

\section{EXPERIMENTS}

\section{A. Preliminary Experiment}

$1 \mathrm{~km}$ mesh size of Global Data Assimilation System: GDAS data is used for truth data of geophysical parameters. Rectangle area is extracted as a test site. The two corners are as follows,

15 degree N, 125 degree East

30 degree N, 135 degree East

south east china sea area. AMSR data used for the experiments is shown in Fig.4. Aqua/AMSR-E which is acquired at around 6 a.m. Japanese local time on 25 April in 2004 is used for the experiments. Rectangle in the Fig. 4 shows test site.

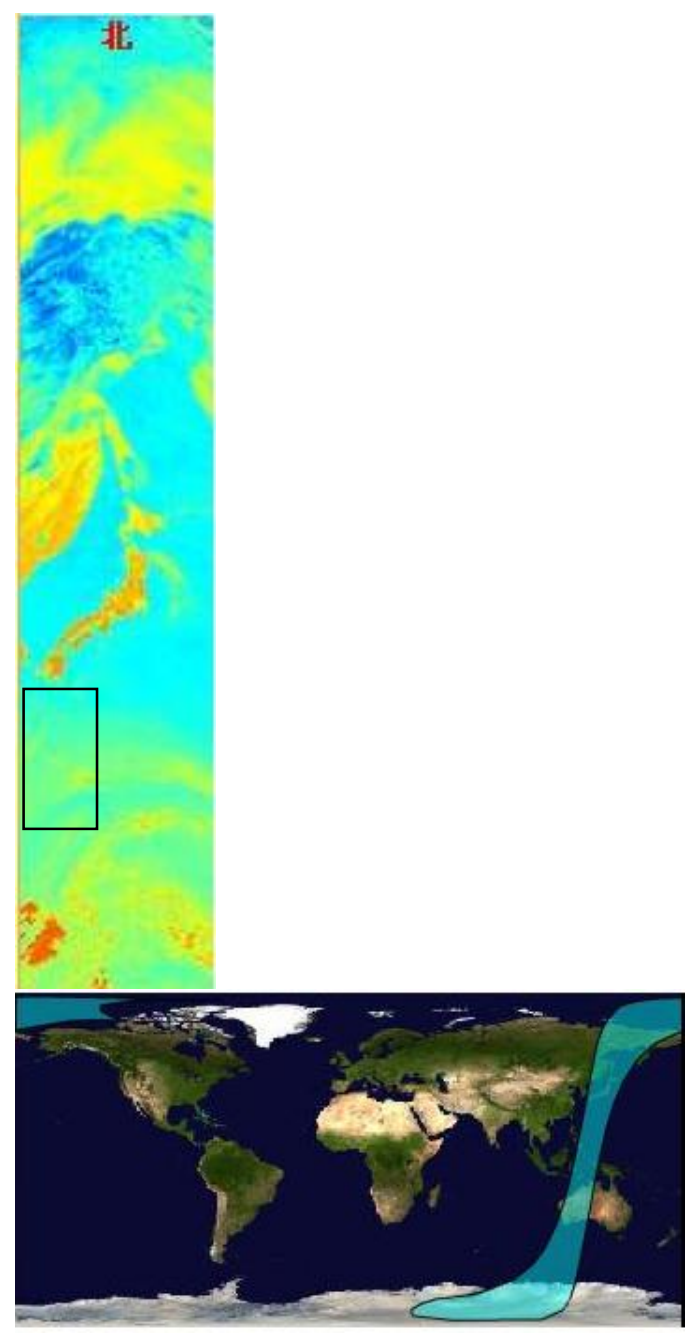

(a)Browse $\quad$ (b) Footprint

Figure 4 AQUA/AMSR-E data used acquired at 17:00 UT on April 25 in 2004.

One of the conventional methods is regressive equation as shown in equation (5).

$P_{j}=c_{0 j}+\sum_{i=1}^{l} c_{i j} T_{B i}$ 
where $T_{B i}$ denotes observed brightness temperature with AMSR frequency channel $\mathrm{i}$ while $\mathrm{j}$ denotes geophysical parameter and $c_{i j}$ are regressive coefficients. Using AMSR data (AQUA/AMSR-E data used acquired at 17:00 UT on April 25 in 2004) and the corresponding GDAS data, regressive equation is created as follows,

$$
\begin{aligned}
\varepsilon_{\mathrm{H}}= & 3.474 \times 10^{-4} W^{2}+2.906 \times 10^{-3} W \\
& +1.274 \times 10^{-5} T^{2}-7.343 \times 10^{-3} T+1.662, \\
\varepsilon_{\mathrm{V}}= & 1.468 \times 10^{-4} W^{2}-0.638 \times 10^{-3} W \\
& +2.129 \times 10^{-5} T^{2}-1.226 \times 10^{-2} T+2.948,
\end{aligned}
$$

where $\varepsilon$ denotes the emissivity. The suffixes $H$ and $V$ mean horizontal and vertical polarizations. Such these relations between the emissivity and SST as well as wind speed are used in the estimation of brightness temperature. Geophysical parameters of the test site are shown in Table 1. Also regressive analysis between geophysical parameters and brightness temperature is conducted. Table 2 shows the regressive coefficients.

Scatter diagrams for sea surface temperature, ocean wind, water vapor are shown in Fig.5 (a), (b), (c), respectively. Horizontal axes of Fig.5 are GDAS data derived geophysical parameter values while vertical axes show AMSR derived geophysical parameters. Linear approximation functions are also shown in the figure. There are systematic differences between GDAS and AMSR derived geophysical parameters in particular for ocean wind.

TABLE I. MEAN AND VARIANCE OF THE GEOPHYSICAL PARAMETERS FOR THE TEST SITE

\begin{tabular}{|l|l|l|}
\hline Geophysical Parameter & Mean & Variance \\
\hline Sea Surface Temperature & $298.7[\mathrm{~K}]$ & 6.1 \\
\hline Ocean Wind & $6.0[\mathrm{~m} / \mathrm{s}]$ & 2.5 \\
\hline Water Vapor & $24.4[\mathrm{~mm}]$ & 29.9 \\
\hline
\end{tabular}

TABLE II. REGRESSIVE COEFFICIENTS FOR GEOPHYSICAL PARAMETER ESTIMATION

\begin{tabular}{|l|l|l|}
\hline Sea Surface Temp. & Ocean Wind & Water Vapor \\
\hline $\mathrm{C} 01: 178.15$ & $\mathrm{C} 02: 102.21$ & $\mathrm{C} 03:-176.88$ \\
\hline $\mathrm{C} 11: 0.7413$ & $\mathrm{C} 12:-0.4719$ & $\mathrm{C} 13: 0.3383$ \\
\hline $\mathrm{C} 21:-0.2994$ & $\mathrm{C} 22: 0.4831$ & $\mathrm{C} 23:-0.2257$ \\
\hline $\mathrm{C} 31:-0.7920$ & $\mathrm{C} 32: 0.1768$ & $\mathrm{C} 33-1.6291$ \\
\hline $\mathrm{C} 41: 0.2522$ & $\mathrm{C} 42:-0.5609$ & $\mathrm{C} 43: 0.8949$ \\
\hline $\mathrm{C} 51: 2.5049$ & $\mathrm{C} 52:-0.0124$ & $\mathrm{C} 53: 5.6032$ \\
\hline
\end{tabular}

\begin{tabular}{|l|l|l|}
\hline $\mathrm{C} 61:-1.2528$ & $\mathrm{C} 62: 0.2142$ & $\mathrm{C} 63:-2.8837$ \\
\hline $\mathrm{C} 71:-1.5317$ & $\mathrm{C} 72:-0.4605$ & $\mathrm{C} 73:-2.8433$ \\
\hline $\mathrm{C} 81: 0.8166$ & $\mathrm{C} 82: 0.2954$ & $\mathrm{C} 83: 1.4401$ \\
\hline
\end{tabular}

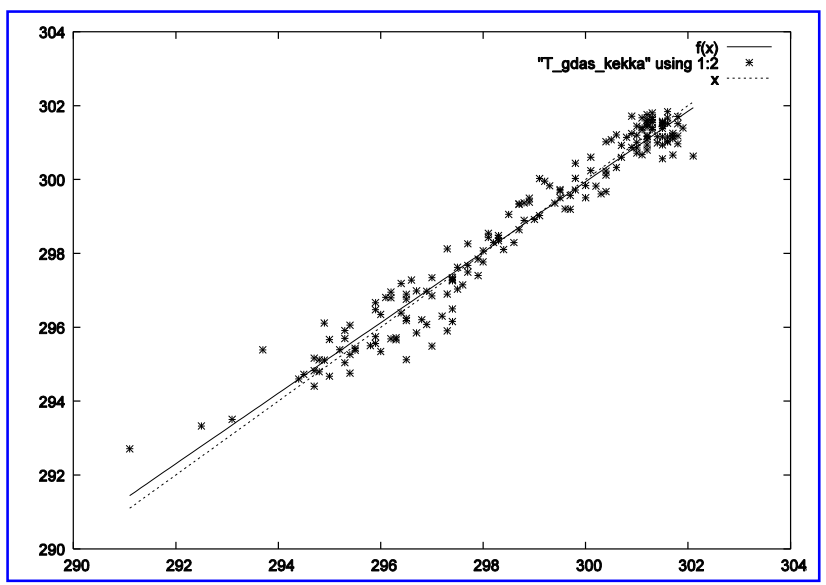

(a)Sea Surface Temperature

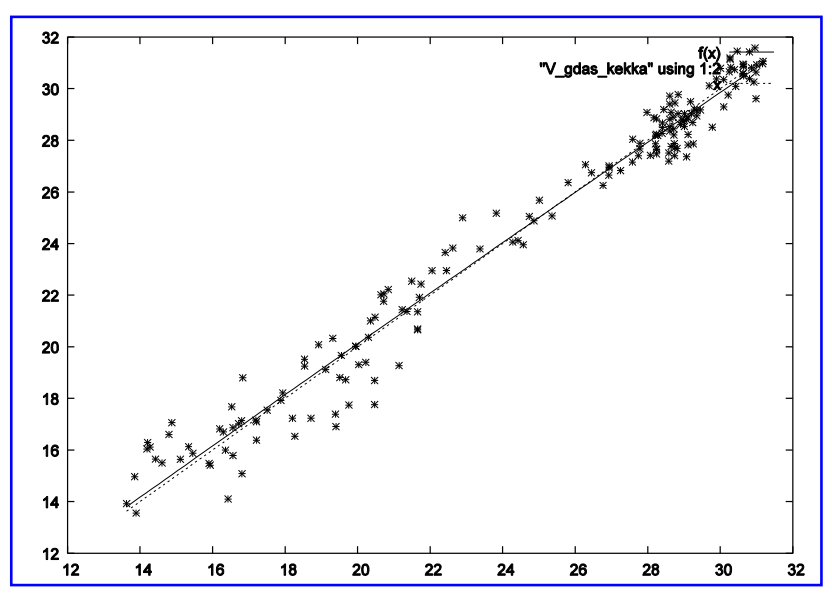

(b)OceanWind

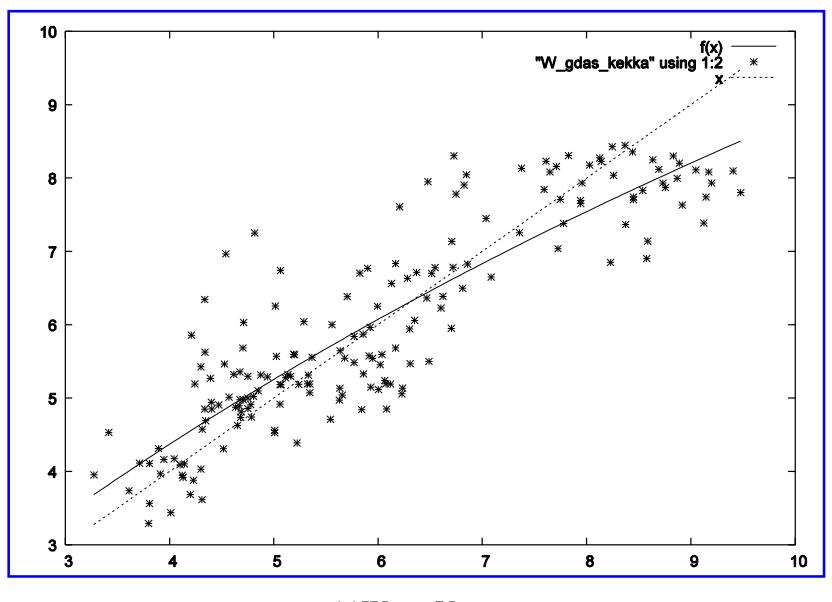

(c)Water Vapor

Figure 5 Scatter diagrams for sea surface temperature, ocean wind, water vapor 
Also regressive errors for these geophysical parameters are shown in Table 3.

TABLE III. REGRESSIVE ERRORS (RMS ERROR)

\begin{tabular}{|l|l|}
\hline Geophysical Parameters & RMS Error \\
\hline Sea Surface Temperature & $0.530[\mathrm{~K}]$ \\
\hline Ocean Wind & $0.754[\mathrm{~m} / \mathrm{s}]$ \\
\hline Water Vapor & $0.899[\mathrm{~mm}]$ \\
\hline
\end{tabular}

\section{B. Estimation Accuracy of the Proposed Method}

Simulated Annealing: SA utilized proposed method is used to minimizing the aforementioned RMS difference between model based and the actual brightness temperature data. Fig. 6 shows scatter diagrams between GDAS derived geophysical parameter values and those for the proposed method. Scatter diagrams for sea surface temperature, ocean wind, water vapor are shown in Fig.6 (a), (b), (c), respectively. Horizontal axes of Fig.6 are GDAS data derived geophysical parameter values while vertical axes show those derived geophysical parameters by the proposed method. Meanwhile, Fig.6 (d) shows convergence processes for these geophysical parameters. As shown in the figure, RMS difference of estimated and GDAS derived geophysical parameter values decreases in comparison to the conventional regressive analysis based method. Trends of scatter diagrams for these geophysical parameters are almost same.

Vertical axis of Fig.6 (d) shows residual error of SA. Residual errors for these geophysical parameter decreases sharply until the number of iteration is $10^{6}$, then gradually decreases beyond that. In particular, residual error for sea surface temperature decreases gradually until the number of iteration is over $10^{7}$. It still decreases monotonically.

\section{Simultaneous Estimation of Geophysical Parameters}

Some of geophysical parameters are highly correlated. For instance, there is much evaporation in high sea surface temperature areas, then water vapor shows also high. The following geophysical parameter estimation method is proposed,

(1) Estimate one geophysical parameter (A), then the other geophysical parameter (B) is estimated with the constraint of the previously estimated geophysical parameter (A),

(2) Then estimate the geophysical parameter (A) with the constraint of the estimated geophysical parameter (B),

(3) Repeat the processes (1) and (2) until the residual error is less than the prior determined certain value.
This method is referred to the simultaneous estimation method hereafter. RMS error of geophysical parameter estimation by the simultaneous estimation method is shown in Table 4.

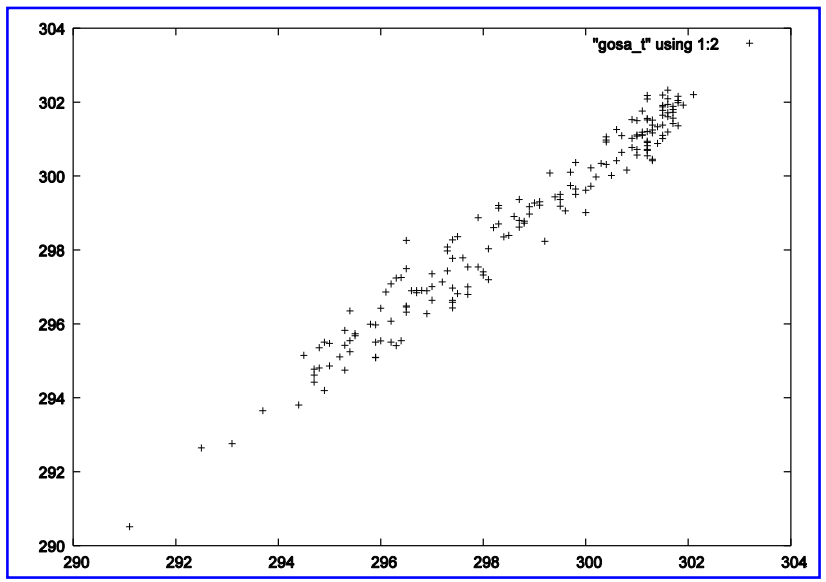

(a)Sea Surface Temperature

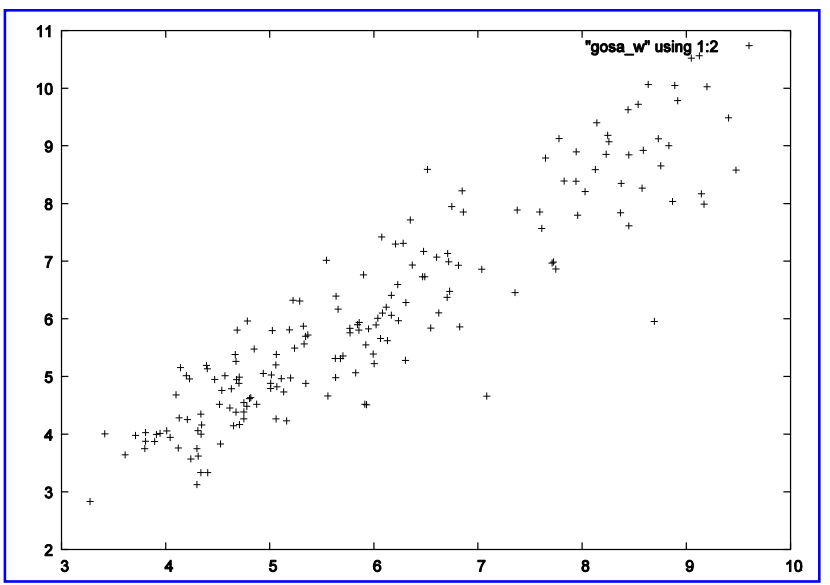

(b)Ocean Wind Speed

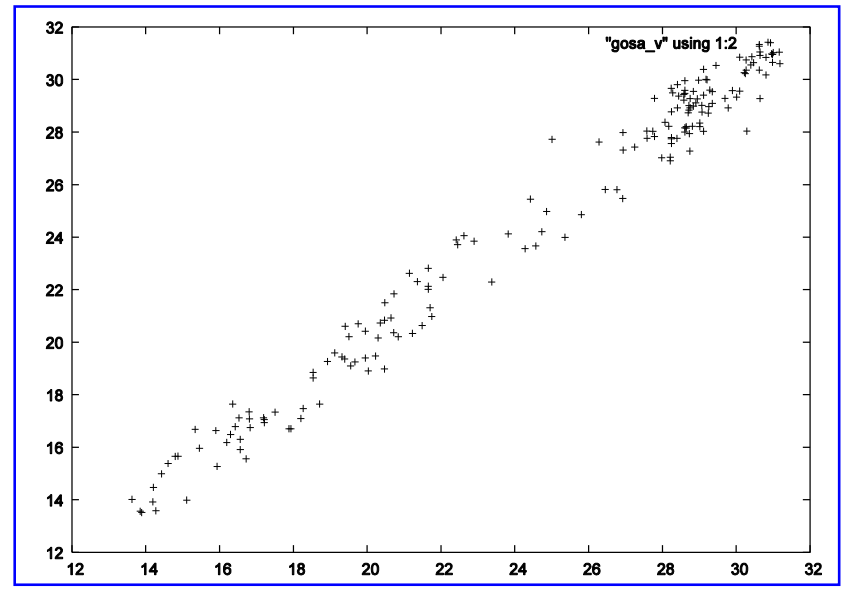

(c)Water Vapor 


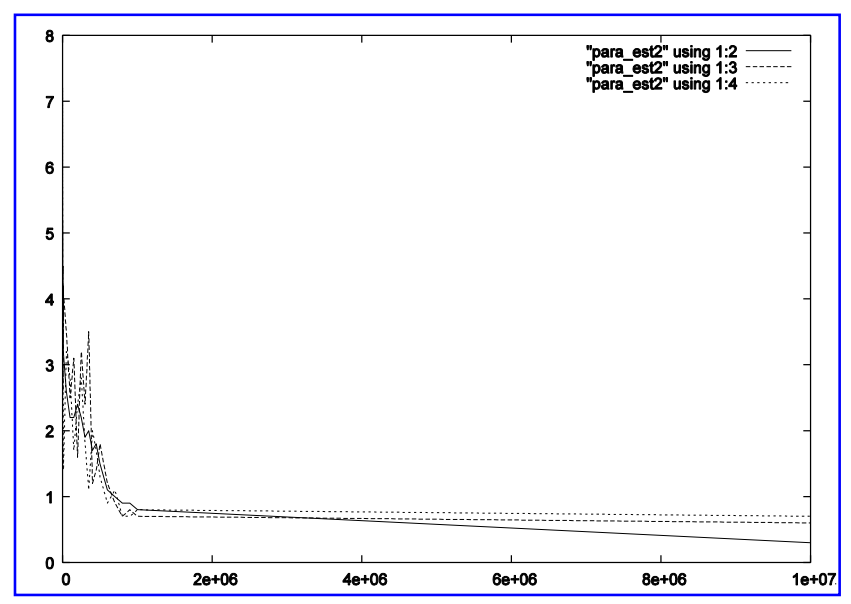

(d)Convergence Processes

Figure 6 Scatter Diagrams between GDAS derived geophysical parameter values and those derived from the proposed method.

TABLE IV. RMS ERROR OF GEOPHYSICAL PARAMETER ESTIMATIONS BY THE SIMULTANEOUS ESTIMATION METHOD

\begin{tabular}{|l|l|}
\hline Geophysical parameters & RMS Error \\
\hline Sea Surface Temperature & $\begin{array}{l}0.632[\mathrm{~K}] \\
0.846[\mathrm{~m} / \mathrm{s}]\end{array}$ \\
Ocean Wind & $0.621[\mathrm{~K}]$ \\
\hline Sea Surface Temperature & $0.853[\mathrm{~mm}]$ \\
Water Vapor & $0.472[\mathrm{~m} / \mathrm{s}]$ \\
\hline Ocean Wind & $0.565[\mathrm{~mm}]$ \\
\hline Water Vapor & \\
\hline
\end{tabular}

Also these three geophysical parameters can be estimated simultaneously. RMS errors for these geophysical parameters estimated by the simultaneous estimation method with three geophysical parameters are shown in Table 5.

TABLE V. RMS ERROR OF GEOPHYSICAL PARAMETER VALUES FOR THE PROPOSED METHOD

\begin{tabular}{|l|l|}
\hline Geophysical parameters & RMS Error \\
\hline Sea Surface Temp. & $0.373[\mathrm{~K}]$ \\
\hline Ocean Wind & $0.731[\mathrm{~m} / \mathrm{s}]$ \\
\hline Water Vapor & $0.787[\mathrm{~mm}]$ \\
\hline
\end{tabular}

In comparison to the RMS error of Table 4, RMS errors of the simultaneous estimation method for ocean wind speed and sea surface temperature are improved. On the other hand, water vapor estimation accuracy in Table 5 shows some degradation comparing to the combination between ocean wind speed and water vapor in Table 4. This accuracy, however, is still better than the conventional regressive analysis based method.

\section{CONCLUSION}

Method for geophysical parameter estimations with microwave radiometer data based on Simulated Annealing: SA is proposed. Geophysical parameters which are estimated with microwave radiometer data are closely related each other. Therefore simultaneous estimation makes constraints in accordance with the relations. As results, it is found that the proposed method is superior to the conventional regressive analysis based method by 27,25 , and $22 \%$ improvements for sea surface temperature, ocean wind speed, and water vapor, respectively. Simulated Annealing which allows find global optimum solution is used for improvement of estimation accuracy in the near future.

\section{ACKNOWLEDGMENT}

The author would like to thank Jun Sakakibara for his effort to experiments.

\section{REFERENCES}

[1] Kohei Arai and J.Sakakibara, Estimation of SST, wind speed and water vapor with microwave radiometer data based on simulated anealing, Advances in Space Research, 37, 12, 2202-2207, 2006

[2] K.Tachi, Kohei Arai and Y.Satoh, Advanced Microwave Scanning Radiometer -Requirements and Preliminary Design Study-, IEEE Trans.on Geoscience and Remote Sensing, Vol.27, No.2, pp.177-183, Jan.1989.

[3] Debue, R. Polar Molecules, Chemical Catalog, New York, 1929.

[4] Cole, K.S., Cole, R.H. Dispersion and absorption in dielectrics. J. Chem. Phys. 9, 341-351, 1941.

[5] Cox, C.S., Munk, W.H. Measurement of the roughness of the sea surface from photographs of the sun_s glitter. J. Opt. Sci. Am. 44, 838-850, 1954.

[6] Wilheit, T.T., Chang, A.T.C. An algorithm for retrieval of ocean surface and atmospheric parameters from the observations of the Scanning Multichannel Microwave Radiometer (SMMR). Radio Sci. 15, 525-544, 1980.

[7] Waters, J.R. Absorption and emission by atmospheric gasses. in: Meeks, M.L. (Ed.), Methods of Experimental Physics, vol. 12B.Academic, Orland, 1976 (Chapter 2.3).

[8] Dong, SF; Sprintall, J; Gille, ST, Location of the antarctic polar front from AMSR-E satellite sea surface temperature measurements, JOURNAL OF PHYSICAL OCEANOGRAPHY, Nov 2006, 2075-2089.

[9] Konda, M., A. Shibata, N. Ebuchi, and K. Arai, An evaluation of the effect of the relative wind direction on the measurement of the wind and the instantaneous latent heat flux by Advanced Microwave Scanning Radiometer, J. Oceanogr., vol. 62, no. 3, pp. 395-404, 2006.

[10] Cosh, M. H., T. J. Jackson, R. Bindlish, J. Famiglietti, and D. Ryu, A comparison of an impedance probe for estimation of surface soil water content over large region, Journal of Hydrology, vol. 311, pp. 49-58, 2005.

[11] Wentz, F. AMSR Ocean Algorithm, second version of ATBD, NASA/GSFC, 2000.

\section{AUTHORS PROFILE}

Kohei Arai, He received BS, MS and PhD degrees in 1972, 1974 and 1982, respectively. He was with The Institute for Industrial Science, and Technology of the University of Tokyo from 1974 to 1978 also was with National Space Development Agency of Japan (current JAXA) from 1979 to 1990. During from 1985 to 1987, he was with Canada Centre for Remote Sensing as a PostDoctoral Fellow of National Science and Engineering Research Council of Canada. He was appointed professor at Department of Information Science, Saga University in 1990. He was appointed councilor for the Aeronautics and Space related to the Technology Committee of the Ministry of Science and Technology during from 1998 to 2000. He was also appointed councilor of Saga University from 2002 and 2003 followed by an executive councilor of the Remote Sensing Society of Japan for 2003 to 2005. He is an adjunct professor of University of Arizona, USA since 1998. He also was appointed vice chairman of the Commission "A" of ICSU/COSPAR in 2008. He wrote 30 books. 